\title{
THE CORRECTION OF FOOT DROP IN LEPROSY*
}

\author{
A. Grace Warren, Hong Kong \\ From the Hay Ling Chau Leprosarium, Hong Kong
}

Foot drop from paralysis of the muscles of the anterior and lateral compartments of the leg is common in leprosy. Often associated with anaesthesia, it is a challenge to the surgeon who seeks to rehabilitate the patient. The patient, unaware of unusual stresses on his foot because of the neurotrophic lesions, may allow a deforming force to continue until an ulcer is formed; hence it is of the utmost importance that any deformity of the foot in a patient with leprosy should be so completely corrected that no other deformity or disability will occur as a result of surgery (Fritschi and Brand 1957).

Many methods of correcting the functional problems associated with a foot drop have been tried with the object of providing a foot that is stable and socially acceptable. Surgical means provide the most permanent correction and give the best cosmetic results (Ober 1933). Transfer of the tibialis posterior tendon to the front of the foot through the interosseous membrane has proved satisfactory, and in most patients is devoid of serious complications (Gunn and Molesworth 1957, Brand 1964). Nevertheless, in the Chinese patients at the Hay Ling Chau Leprosarium a regularly recurring list of complications has followed the routine use of this method, when followed up for five to six years.

\section{COMPLICATIONS OF TIBIALIS POSTERIOR TRANSFER}

The commonest complications encountered are as follows. 1) Inadequate elevation of the foot because of undue lengthening of the tendon. 2) Inversion or eversion of the foot related to the placement of the new insertion and the pull on any remaining muscles; 3 ) talonavicular collapse (Andersen 1964, Paterson and Job 1964, Harris and Brand 1966), which may occur without operation and is not of necessity associated with any obvious infection. In reconstructive surgery the first indication occurs some two to four weeks after the removal of the plaster, when the patient starts to walk again. The foot becomes warm and slightly swollen but there is usually no discomfort. A radiograph may show osteoporosis only at this time but if walking is allowed freely and radiography is repeated in six weeks the early signs of bone breakdown will often be seen. Early detection and immobilisation for up to six months in a walking plaster can lead to complete recovery without deformity; neglect may lead to increasing bone destruction and to loss of the arch with lateral deviation of the forefoot. This condition of talo-navicular collapse is believed to be caused by unnoticed injury to the anaesthetic foot. However, it has been assumed that surgical intervention with the tarsal bones must increase the tendency to bone breakdown after surgery. The new technique described has therefore avoided tendon-to-bone union and has utilised a tendon-totendon technique, which requires only three weeks in plaster and therefore there is less osteoporosis. 4) Instability of the talo-navicular joint which may be associated with some breakdown of the cuboid bone or the calcaneus and results in lateral deviation on the forefoot. This is assumed to be connected with removal of the support of the talo-navicular joint that is provided by the tibialis posterior tendon (Last 1963). 5) Dropped toes caused by laxity of the tendons of the paralysed extensor digitorum longus when the ankle once again assumes the right angled position and the pull of the tendons of the flexor digitorum longus shortened by the dropped foot position. This may cause the patient to walk on the nails of the toes

* Based on a paper presented at the Combined Orthopaedic Meeting in Singapore in August 1966. 
TABLE I

Comparison of the Old and New Methods in Cases 1 and 2

\begin{tabular}{|c|c|c|c|c|c|c|}
\hline $\begin{array}{c}\text { Case } \\
\text { number }\end{array}$ & Side & Sex & $\begin{array}{c}\text { Age in } \\
\text { years }\end{array}$ & $\begin{array}{l}\text { Method and } \\
\text { date of } \\
\text { operation }\end{array}$ & Movement & $\begin{array}{c}\text { Angles before } \\
\text { operation } \\
\text { in degrees }\end{array}$ \\
\hline \multirow{2}{*}{1} & Right & \multirow{2}{*}{ Male } & \multirow{2}{*}{70} & $\begin{array}{c}\text { Old } \\
\text { October } 1964\end{array}$ & $\begin{array}{c}\text { Passive dorsiflexion } \\
\text { Active dorsiflexion } \\
\text { At rest } \\
\text { Active plantar-flexion } \\
\text { Range }\end{array}$ & $\begin{array}{r}85 \\
115 \\
120 \\
5\end{array}$ \\
\hline & Left & & & $\begin{array}{c}\text { New } \\
\text { May } 1965\end{array}$ & $\begin{array}{c}\text { Passive dorsiflexion } \\
\text { Active dorsiflexion } \\
\text { At rest } \\
\text { Active plantar-flexion } \\
\text { Range }\end{array}$ & $\begin{array}{r}\frac{85}{115} \\
128 \\
13\end{array}$ \\
\hline \multirow{2}{*}{2} & Left & \multirow{2}{*}{ Male } & \multirow{2}{*}{31} & $\begin{array}{c}\text { Old } \\
\text { June } 1964\end{array}$ & $\begin{array}{c}\text { Passive dorsiflexion } \\
\text { Active dorsiflexion } \\
\text { At rest } \\
\text { Active plantar-flexion } \\
\text { Range }\end{array}$ & $\begin{array}{r}75 \\
125 \\
140 \\
15\end{array}$ \\
\hline & Right & & & $\begin{array}{c}\text { New } \\
\text { May } 1965\end{array}$ & $\begin{array}{c}\text { Passive dorsiflexion } \\
\text { Active dorsiflexion } \\
\text { At rest } \\
\text { Active plantar-flexion } \\
\text { Range }\end{array}$ & $\begin{array}{r}\frac{88}{110} \\
120 \\
10\end{array}$ \\
\hline
\end{tabular}

which are turned under. 6) Clawed toes, which may result if too strong a pull is given to the toe extensors by suturing these to the mobile section of the active tendino-muscular transfer when there are no muscles to provide flexion of the metatarso-phalangeal joints (Andersen 1961).

\section{PRINCIPLES OF TREATMENT}

With these points in mind a new method of foot drop correction has been evolved with the object of: 1) maintaining the muscular support of the talo-navicular joint; 2) providing tendon-to-tendon union to reduce immobilisation to three weeks; 3 ) leaving the bones of the foot intact; 4) reducing the tendency to dropped toes and clawed toes.

The principle of the modified operation is to leave the distal five centimetres of the tendon of tibialis posterior in situ and to attach this stump to the flexor digitorum longus as the two tendons lie together above the medial malleolus. This means that the flexor digitorum longus will pull on the insertion of the tibialis posterior and so maintain some muscular support of the arch of the foot and the talo-navicular joint. Its power of pull on the toe tips is thus reduced, so that dropped toes are not so likely to occur.

The proximal part of the tendon of tibialis posterior is still available for transfer with the muscle belly, but will not of course reach to the dorsum of the foot. To meet this deficiency further variations of technique have been evolved. The tibialis posterior is attached to the tendon of tibialis anterior at the junction of the middle and lowest thirds of the leg and the tibialis anterior tendon therefore prolongs the tendon of tibialis posterior so that it reaches the medial side of the dorsum of the foot. The lateral side of the foot is provided for by a peroneal slip that is woven through the tibialis anterior to form an inverted $\mathrm{Y}$ distal to the ankle when the tibialis posterior muscle contracts and dorsiflexes the foot-hence there is no active pull on the toe extensors if they are stitched to this peroneal slip and the effect is that of a tenodesis.

Good results cannot be expected if the ankle will not passively move through an adequate range. It is desirable that after surgery the patient should be able actively to lift the toes off 
TABLE I-continued

Comparison of the Old and New Methods in Cases 1 and 2

\begin{tabular}{|c|c|c|c|c|c|c|}
\hline \multirow[b]{2}{*}{3 weeks } & \multicolumn{4}{|c|}{ Angles after operation in degrees } & \multirow[b]{2}{*}{20 months } & \multirow{2}{*}{ Comment } \\
\hline & 7 weeks & 4 months & 7 months & 12 months & & \\
\hline 70 & 70 & 65 & 70 & 70 & 73 & \multirow{10}{*}{$\begin{array}{l}\text { Walks very well now. } \\
\text { Feet previously very } \\
\text { unstable and needed } \\
\text { crutches to walk at al }\end{array}$} \\
\hline 80 & 78 & 70 & 78 & 86 & 85 & \\
\hline 90 & 85 & 75 & 85 & 90 & 90 & \\
\hline 92 & 90 & 95 & 95 & 95 & 100 & \\
\hline 12 & 12 & 15 & 17 & 11 & 15 & \\
\hline 68 & 70 & 70 & 70 & 70 & 75 & \\
\hline 75 & 78 & 82 & 82 & 85 & 90 & \\
\hline 80 & 90 & 90 & 90 & 95 & 95 & \\
\hline 85 & 95 & 95 & 95 & 100 & 105 & \\
\hline 10 & 17 & 13 & 13 & 15 & 15 & \\
\hline 75 & 75 & 70 & 70 & 70 & 70 & \multirow{10}{*}{$\begin{array}{c}\text { Right foot excellent } \\
\text { result. } \\
\text { Left foot revised } \\
\text { in December } 1966 \\
\text { at patient's request. } \\
\text { Now walks very well }\end{array}$} \\
\hline 83 & 83 & 84 & 96 & 90 & 94 & \\
\hline 90 & 95 & 95 & 110 & 105 & 105 & \\
\hline 95 & 100 & 104 & 115 & 110 & 110 & \\
\hline 13 & 17 & 20 & 19 & 20 & 16 & \\
\hline & & & 60 & 65 & & \\
\hline 73 & 80 & 80 & $\begin{array}{l}00 \\
80\end{array}$ & $\begin{array}{l}\text { os } \\
80\end{array}$ & 80 & \\
\hline 76 & 88 & 90 & 90 & 90 & 90 & \\
\hline 80 & 90 & 95 & 95 & 100 & 100 & \\
\hline 7 & 10 & 15 & 15 & 20 & 20 & \\
\hline
\end{tabular}

the ground when he is standing with his heel on the ground. A range of 10 degrees of movement on each side of the midpoint of ankle movement is probably ideal but not necessary in practice. To achieve this it is necessary to be able to dorsiflex the ankle passively to 75 degrees with the knee straight; if this is not possible it is advisable to lengthen the calcaneal tendon.

Measurements-All measurements are taken with the knee straight and the leg parallel with the ground, with increasing values as the foot passes from dorsiflexion (extension) to plantarflexion (flexion). By this method all changes follow a regular transition and one does not need to state if the movement is flexion or extension in each case.

\section{TECHNIQUE}

Through an incision on the medial side of the leg the tendons of tibialis posterior and flexor digitorum longus are displayed and the calcaneal tendon is lengthened if necessary. The tendon of tibialis posterior is divided obliquely so that the distal slip can be sutured into the lateral side of the flexor digitorum longus. There should be no tension on the suture when the ankle is dorsiflexed to 80 degrees and the toes are straight.

The anterior surface of the interosseous membrane is displayed at the level of the junction of the middle and lowest thirds of the tibia, through a curved incision based medially, and the membrane is incised along the tibia. The proximal part of the tibialis posterior tendon is pulled through to the front of the leg. Sufficient fibres of the tibialis anterior muscle are separated from its tendon to allow the tendon of the tibialis posterior to be passed through the hole so made so that the two tendons lie side by side and burying of unsatisfied tendon ends is simplified.

A slip is passed from the peroneus tertius or from the insertion of peroneus brevis to the tibialis anterior tendon at the ankle, and sutured to it so that the tibialis anterior tendon is pulled slightly to the lateral side of the mid-point of the ankle (Fig. 1). This slip can be peroneus brevis, peroneus tertius if it is well defined, or a tendon graft. This provides lateral lift and stability. If the foot is very mobile extra slips may be used passing from the tibialis anterior 
at the ankle to the periosteum of the fifth metatarsal neck. The further distal the fixation, the less likely is inversion or instability. With the hallux straight the tendon of extensor hallucis longus is sutured without tension to the tibialis anterior tendon, distal to its junction with the peroneal slip. To the peroneal slip the toe extensors are sutured without tension when the toes are straight. This will help to prevent dropped toes.

With the knee held at about 40 degrees of flexion, and the ankle dorsiflexed to 75 degrees, the tendons of posterior and tibialis anterior are then sutured together with the greatest tension possible, and all unsatisfied ends are buried. This position is held during final skin closure and until the plaster-of-Paris cast is applied to maintain position.

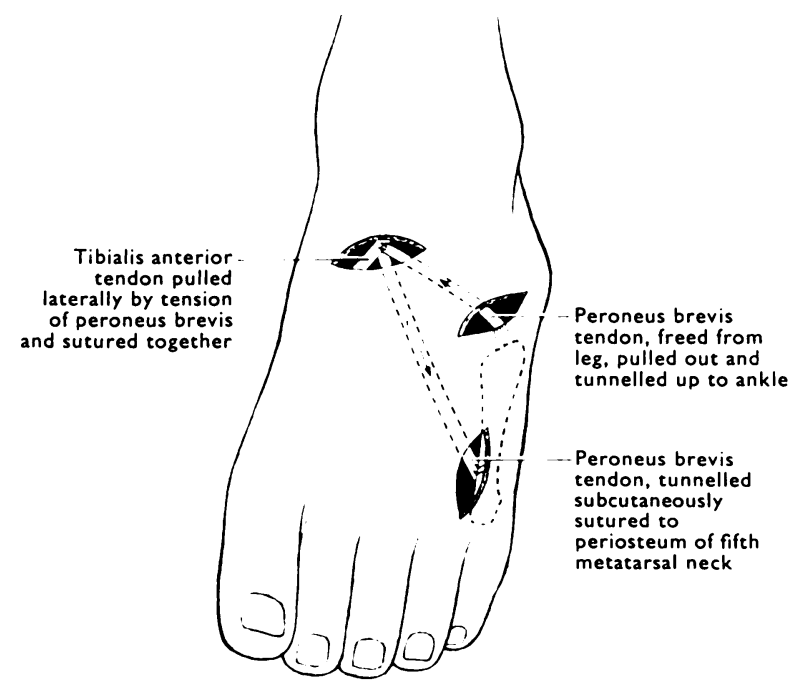

Fig. 1

Diagram to show passage of peroneus brevis from its intact insertion, subcutaneously to the tibialis anterior tendon, and then forward to the fifth metatarsal neck.

The plaster is removed after three weeks, with no weight-bearing, and is converted into a backslab to be worn all the time when the patient is not exercising. Active re-education is started as soon as the plaster is removed, and active control is usually achieved within the first week, when partial weight-bearing is allowed until the patient has learnt to use the transferred muscle against gravity, at which time walking is started. The patient is expected to be walking within three weeks of removal of the plaster - that is six weeks after operation. The backslab is discarded by day once walking is well established but is used at night for a further three or four weeks.

\section{SELECTION OF CASES}

The first two patients had bilateral foot drop. They had previously had a corrective operation for one foot, using a previous technique. The second foot was done with the new method. In both patients the peroneus brevis was used for the lateral slip, and in both the toes were still fairly mobile. No complications occurred and both patients preferred the "new method" without knowing it was technically different. In Table I the range of movement of both pairs of feet as recorded over a period of twenty months is set out for comparison. It will be noticed that slackening continues to occur over a long period of time for both methods, but that by the end of four months the foot is fairly stable.

These two patients were out of plaster and evaluated before further cases were done by similar methods. Because the first two feet thus treated functioned well it was decided to do 
TABLE II

Angles of Movement in Recent Cases

\begin{tabular}{|c|c|c|c|c|c|c|c|c|c|}
\hline \multirow[b]{2}{*}{$\begin{array}{c}\text { Case } \\
\text { number }\end{array}$} & \multirow[b]{2}{*}{ Sex } & \multirow[b]{2}{*}{$\begin{array}{l}\text { Age } \\
\text { in } \\
\text { years }\end{array}$} & \multirow[b]{2}{*}{$\begin{array}{l}\text { Follow-up } \\
\text { in } \\
\text { months }\end{array}$} & \multicolumn{5}{|c|}{ Angles in degrees } & \multirow[b]{2}{*}{ Comment } \\
\hline & & & & $\begin{array}{l}\text { Passive } \\
\text { dorsi- } \\
\text { flexion }\end{array}$ & $\begin{array}{l}\text { Active } \\
\text { dorsi- } \\
\text { flexion }\end{array}$ & At rest & $\begin{array}{l}\text { Active } \\
\text { plantar- } \\
\text { flexion }\end{array}$ & Range & \\
\hline 3 & Male & 25 & 13 & 75 & 88 & 95 & 102 & 14 & Very satisfactory. Walks well \\
\hline 4 & Male & 33 & 11 & 73 & 85 & 95 & 100 & 15 & $\begin{array}{l}\text { Good walk after tibialis } \\
\text { anterior shortened }\end{array}$ \\
\hline 5 & Male & 42 & 10 & 75 & 95 & 100 & 110 & 15 & $\begin{array}{l}\text { Good function. Consideration } \\
\text { must be given to loss of great toe }\end{array}$ \\
\hline 6 & Male & 46 & 9 & 75 & 88 & 95 & 100 & 12 & $\begin{array}{l}\text { Very satisfactory with } \\
\text { almost normal gait }\end{array}$ \\
\hline 7 & Female & 52 & 9 & 75 & 85 & 90 & 97 & 12 & $\begin{array}{l}\text { Some inversion after initial } \\
\text { surgery corrected by } \\
\text { tightening of the lateral slip }\end{array}$ \\
\hline 8 & Female & 57 & 9 & 70 & 85 & 97 & 117 & 32 & $\begin{array}{l}\text { Excellent range and a fair gait. } \\
\text { Other foot arthrodesed }\end{array}$ \\
\hline 9 & Male & 36 & 9 & 70 & 88 & 95 & 105 & 17 & $\begin{array}{l}\text { Very slow to re-educate. } \\
\text { Now walks very well }\end{array}$ \\
\hline 10 & Female & 30 & 9 & 70 & 80 & 90 & 97 & 17 & $\begin{array}{l}\text { Short foot from loss of toes. } \\
\text { Walks quite well }\end{array}$ \\
\hline 11 & Male & 36 & 8 & 70 & 80 & 90 & 105 & 25 & $\begin{array}{l}\text { Some lateral instability } \\
\text { corrected when peroneus brevis } \\
\text { was used to replace peroneus } \\
\text { tertius. Now walks well }\end{array}$ \\
\hline 12 & Male & 25 & 6 & 73 & 85 & 95 & 98 & 13 & $\begin{array}{l}\text { Foot very stable. Patient } \\
\text { satisfied though only } \\
\text { small range of movement }\end{array}$ \\
\hline 13 & Male & 33 & 6 & 68 & 80 & 86 & 93 & 13 & $\begin{array}{l}\text { Foot rather stiff but patient } \\
\text { satisfied and walks quite well }\end{array}$ \\
\hline
\end{tabular}

all subsequent operations by this method. A total of fifteen more cases were done in the following ten months. The movements found in those with a follow-up of six months or more are given in Table II with comments on function.

\section{DISCUSSION}

It is considered that the range of movement achieved by this transfer adequately provides for the function of the foot. Minor variations in the method of stabilisation of the lateral side of the foot were tried but the peroneus brevis has usually proved the most adequate lateral stabiliser.

One case only had increased warmth and slight swelling about two weeks after removal of the plaster. This lasted for two days only and did not recur when walking was resumed. Radiographs taken at least three months after operation in each case have shown no signs of bone breakdown.

The tendency to drop toes is difficult to assess. No patient so far has complained of the development of dropped or clawed toes but a continued watch must be kept for these complications.

There has been no sign of talo-navicular instability in any case. This usually manifests itself within six months of operation. Only time will tell whether the reactivation of the distal 
stump of the tibialis posterior tendon does in fact reduce deformity and if the use of the flexor digitorum longus for activation of this stump reduces the incidence of dropped toes and collapse of the long arch of the foot.

It has been found that this procedure is technically easier than other methods and takes less time.

\section{SUMMARY}

1. The complications following standard tendon transfer to provide active correction of drop foot in Chinese patients with leprosy are reviewed.

2. An alternative method of foot drop correction is described in which reactivation of the remaining distal stump of the tibialis posterior tendon is provided to assist in maintaining the stability of the arch of the foot and to help to prevent dropped toes.

3. A review of thirteen patients is given. The indications are that this method is functionally as good as other methods. So far it has shown none of the complications usual in Chinese patients.

I would like to acknowledge the assistance of our patients and colleagues, without whose help it would have been impossible to develop this alternative method. I would like to thank Professor P. W. Brand and Mr G. M. Bedbrook for their encouragement and $\mathrm{Mr} \mathrm{H}$. Jackson Burrows for his assistance and advice in the preparation of the manuscript.

\section{REFERENCES}

Andersen, J. G. (1961): Plantar Ulcers in Leprosy. Leprosy Review, 32, 16.

ANDersen, J. G. (1964): Foot Drop in Leprosy. Leprosy Review, 35, 41.

Brand, P. W. (1964): Deformity in Leprosy. In Leprosy in Theory and Practice. Second edition, p. 447. Edited by R. G. Cochrane and T. F. Davey. Bristol: John Wright \& Sons Ltd.

Fritschi, E. P., and Brand, P. W. (1957): The Place of Reconstructive Surgery in the Prevention of Foot Ulceration in Leprosy. International Journal of Leprosy, 25, 1.

Gunn, D. R., and Molesworth, B. D. (1957): The Use of Tibialis Posterior as a Dorsiflexor. Journal of Bone and Joint Surgery, 39-B, 674.

Harris, J. R., and Brand, P. W. (1966): Patterns of Disintegration of the Tarsus in the Anaesthetic Foot. Journal of Bone and Joint Surgery, 48-B, 4.

LAST, R. J. (1963): Anatomy, Regional and Applied. Third edition, p. 270. London: J. \& A. Churchill Ltd.

Ober, F. R. (1933): Tendon Transplantation in the Lower Extremity. New England Journal of Medicine, 209, 52.

Paterson, D. E., and JoB, C. K. (1964): Bone Changes and Absorption in Leprosy. In Leprosy in Theory and Practice. Second edition, chapter 26, p. 425. Edited by R. G. Cochrane and T. F. Davey. Bristol: John Wright \& Sons Ltd. 